\title{
Editorial
}

\section{What can higher education contribute to improving social mobility in the UK?}

Jane Andrews, Engineering Systems Management MSc Programme Director, Engineering \& Applied Science, Aston University.

Joan O’ Mahony, Academic Development Officer, Leadership \& Strategy, Higher Education Academy. York

At a time when the UK may slowly be emerging out of what, for many in higher education, has been a period of 'unprecedented change' (Universities UK, 2012) in which institutions have found themselves having to balance increases in student expectations and demands against decreases in funding and resources, this special edition focuses on an issue that is becoming ever-more important - that of the relationship between social mobility and higher education. Drawing upon the findings of the Higher Education Academy's March 2013 Conference: What can higher education contribute to improving social mobility in the UK? , the six papers gathered here give between them a clear indication of the proactive and synergetic manner in which the sector is responding to the resource and funding challenges which it currently faces.

Perhaps the most important of these challenges arise from the funding of mainly undergraduate programmes and the recent shift in the burden of this funding from society and government onto individual students, their families and on some occasions, their employers. This shift in emphasis has raised serious concerns about future access to, and equality within, higher education. Indeed many institutions are experiencing lower numbers of applications, heightening existent fears about stagnating social mobility and elitism within the sector. Moreover, current students are beginning to view themselves as consumers, with colleagues anecdotally noting a marked change in attitude whereby a small number of undergraduates have begun to view their degree as something they will have paid for - as opposed to earned. It is this growing shift towards consumerist principles that makes issues of access, retention, attainment and progression of particular relevance across today's sector. Indeed, as higher education providers find themselves considering how best to deal with the challenges associated with change, the possibility that 'non-traditional' students may be put off by the rising costs of education is something that urgently needs addressing.

The Higher Education Academy's two-day residential conference provided an ideal opportunity for such concerns to be aired and debated, with participants from across the four UK nations encouraged to present new data and raise new perspectives (Porter, 2013) on the role of higher education in improving social mobility. The conference's mix of invited keynote and panel speakers, paper and workshop presenters, and perhaps most importantly, a student 'jury' comprising 12 students from across the UK collaborated over two days to examine and explore a number of priority issues. The issues debated included: how current and projected changes to funding impact on part-time students and students from underrepresented, disadvantaged and 'non-traditional' groups; the role of students in enhancing the quality and outcomes of the higher education experience for these particular sets of 
learners; and, how access to employment, graduate careers and the professions can be achieved across all student groups.

In selecting papers for this special edition the editors considered a number of key questions. In particular they focused on: What stops potential students from continuing on to higher education? What it is that encourages non-traditional learners to go to university or college? What keeps students at university or college, and what helps them to succeed once they are there? These are all questions vital to sustaining and promoting social mobility.

The first paper by Woodfield, May and Van der Sluis's asks 'how progression agreements (PAs) promote social mobility through improving pathways to the professions and vocational careers.' The paper argues that while higher education providers are rightly interested in students' transitions into employment, they cannot control the labour market and thus have limited influence on whether, post HE, graduates are, or are not, socially mobile. However, there are many factors which ultimately determine a student's future social mobility, Woodfield et al identify several extrinsic influences on social mobility including the student's original subject choice, their actual attainment while in higher education as well as recruitment practices in organisations and the range of routes to the professions.

While Woodfield, May and Van der Sluis note that the horizons of students' with progression agreements can sometimes seem limited, the second paper by Marshall focuses on students with a clear ambition to access university. Examining the factors that affect degree success for non-traditional students, Marshall suggests that the usual predictors of success used by universities in offering student places ('A' level grades and subjects studied) are inadequate when it comes to capturing the potential of non-traditional students. Indeed, she argues that in determining entry, A level grades, are not as useful as other indicators of ability and concludes that "for social mobility to be a reality in $\mathrm{HE}$ there needs to be more acceptance of alternative routes rather than the standard A level route at 18”.

Moving away from the issue of routes into university, the next paper, by Andreanoff, draws attention to the value of peer-mentoring in combating issues around transition for first year students. Grounded in the work of Andrews \& Clark (2011) the paper looks at a small mentoring programme specifically aimed at supporting students at high risk of attrition. What is most unique about the mentoring programme is that it combined electronic and face-to-face mentoring to enable each pairing (mentor and mentee) to decide the exact nature and detail of the support given. Andreanoff's research is a timely reminder of the valuable role that students can play in supporting other students both at the time of transition but also as the term progresses. Given such support students are provided with the means to succeed and, in the long term, are able to become socially mobile.

While there can be little argument that peer mentoring can be enormously beneficial to student success and thus inevitably impact social mobility, it is clear that more work needs to be done on understanding the factors that foster successful mentoring. The fourth paper in this special edition by Noakes, May, Van der Sluis and Gay discusses research into the characteristics of successful mentoring partnerships, looking closely at the characteristics of 'matched' peer mentoring. The paper by 
Noakes et al. provides an interesting insight into how students experience mentoring and goes some way to suggest that 'familiarity' and not necessarily 'similarity' is a key contributing factor to positive outcomes in mentor-protégé relationships. The ideas in Noakes et al's. paper could potentially offer valuable food for thought for those offering graduate-student mentoring with its findings leading to the suggestion that social mobility might best be facilitated if students are matched with a graduate who, rather than being from a similar demographic and socio-economic background offers familiarity in terms of subject discipline perhaps, rather than a similar gender or ethnicity.

Continuing the theme of support given to non-traditional students and further developing the work of Thomas (2012) the fifth paper in this edition, by Van der Sluis, May, Locke and Hill looks at the role of Academic Support Centres (ASCs) in imbuing students from non-traditional backgrounds with a sense of belonging, ultimately enhancing their potential for social mobility. Arguing that students who use ASCs are most likely to seek help with academic writing, the paper suggests that those students who seek such support are more likely to progress through university irrespective of their background. The paper concludes by noting the importance of offering a multifaceted approach to student support, indicating that ASCs work best if they offer several initiatives concurrently, including virtual mentoring, peer assisted learning and support with mathematics. The issue of supporting students from nontraditional backgrounds is, arguably, key to providing such students with the means to at university and ultimately become socially mobile.

Whilst previous studies have highlighted the value of supporting students from nontraditional backgrounds as a means of dealing with attrition, the final paper by RoseAdams provides an interesting insight into the implications of 'non-completion' in terms of social mobility. Drawing on the dataset of a large national study of 86 UK HEIs between 2006 and 2012, Rose-Adams argues that while 'early leaving' is more prevalent among students from 'non-traditional' HE backgrounds, it is even greater for those non-traditional students at high tariff group institutions. Furthermore, since students at high tariff group institutions possess higher tariffs upon entry, it may be argued that strong academic performance on entry does not necessarily translate into university success for non-traditional students. Contextualising his findings within the context of previous research that looks at unequal access to the professions, RoseAdams argues that the risks of attrition for non-traditional students at high tariff institutions suggests an additional layer of inequality in terms of student retention that needs to be addressed; indeed, non-traditional students at these universities face additional barriers to completion and hence are less likely to be socially mobile than other students.

\section{Conclusion}

The six papers in this special issue cover every aspect of the student journey, from entry through to graduation and employment. Many of the concerns raised in these papers echo those discussed by members of the student jury throughout the conference, with issues around social and academic support, personal development and employability representing an important part of the debate throughout the two days. While it is not possible to cover all the conference themes, post conference key 
note, paper presentations and comments from student jurors are available on the HEA's social mobility conference page.

In conclusion, it is expected that this edition will contribute to current debates about the importance of higher education in promoting social mobility, adding to present understanding and offering valuable insights into the value and purpose of education in what is undoubtedly an increasingly competitive and market-driven environment

\section{References}

Andrews, J., \& Clark, R. (2011). Peer Mentoring Works! How Peer Mentoring Enhances Student Success in Higher Education. Birmingham: Aston University

Porter, A. (2013). What can higher education contribute to improving social mobility in the UK? A report summarising the Higher Education Academy's conference on social mobility, March 2013, Manchester. York: Higher Education Academy http://www.heacademy.ac.uk/resources/detail/inclusocial_mobility_conference

Thomas L. (2012). Building student engagement and belonging in higher education at a time of change: Final report of the What Works? Retention and Success Programme. Available from:

http://www.heacademy.ac.uk/assets/documents/retention/what_works_final_report.pd f Accessed 11/8/13.

Universities UK (2012) Patterns \& Trends in UK Higher Education. Available from: http://www.universitiesuk.ac.uk/highereducation/Documents/2012/PatternsAndTrend sinUKHigherEducation2012.pdf Accessed 5/8/13. 